\title{
Atypical dentin dysplasia due to SMOC2 deficiency
}

INSERM

\section{Source}

INSERM. (1999). Orphanet: an online rare disease and orphan drug data base. Atypical dentin dysplasia due to SMOC2 deficiency. ORPHA:314721

A rare, genetic, dentin dysplasia disease characterized by extreme microdontia, oligodontia, and abnormal tooth shape (including globular teeth, incisal notches and double tooth formation). Short roots with a variable pulp phenotype (including taurodontia and flame-shaped pulp), enamel hypoplasia and anterior open bite may also be associated. 